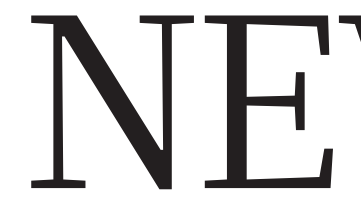

PUbLIC HEALTH Will HIV

prevention pills boost risky

behaviour? p.260
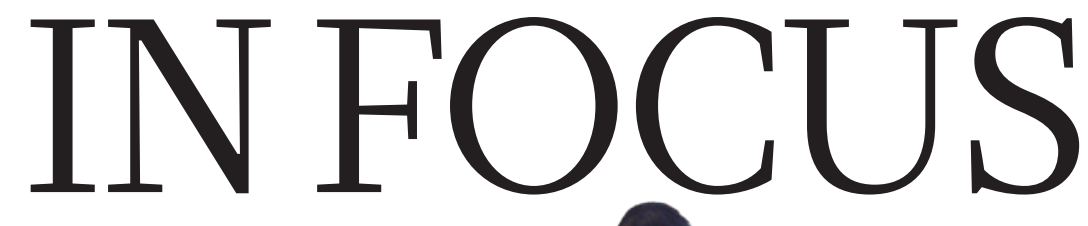

PoLICY US agencies promise to protect scientists from political interference $\mathbf{p . 2 6 2}$
EтHICS Declared 'flawed' a decade ago, infantdeath papers live on $\mathbf{p . 2 6 3}$
ANIMAL BEHAVIOUR

Surveying chimps for signs of culture $\mathbf{p} .270$

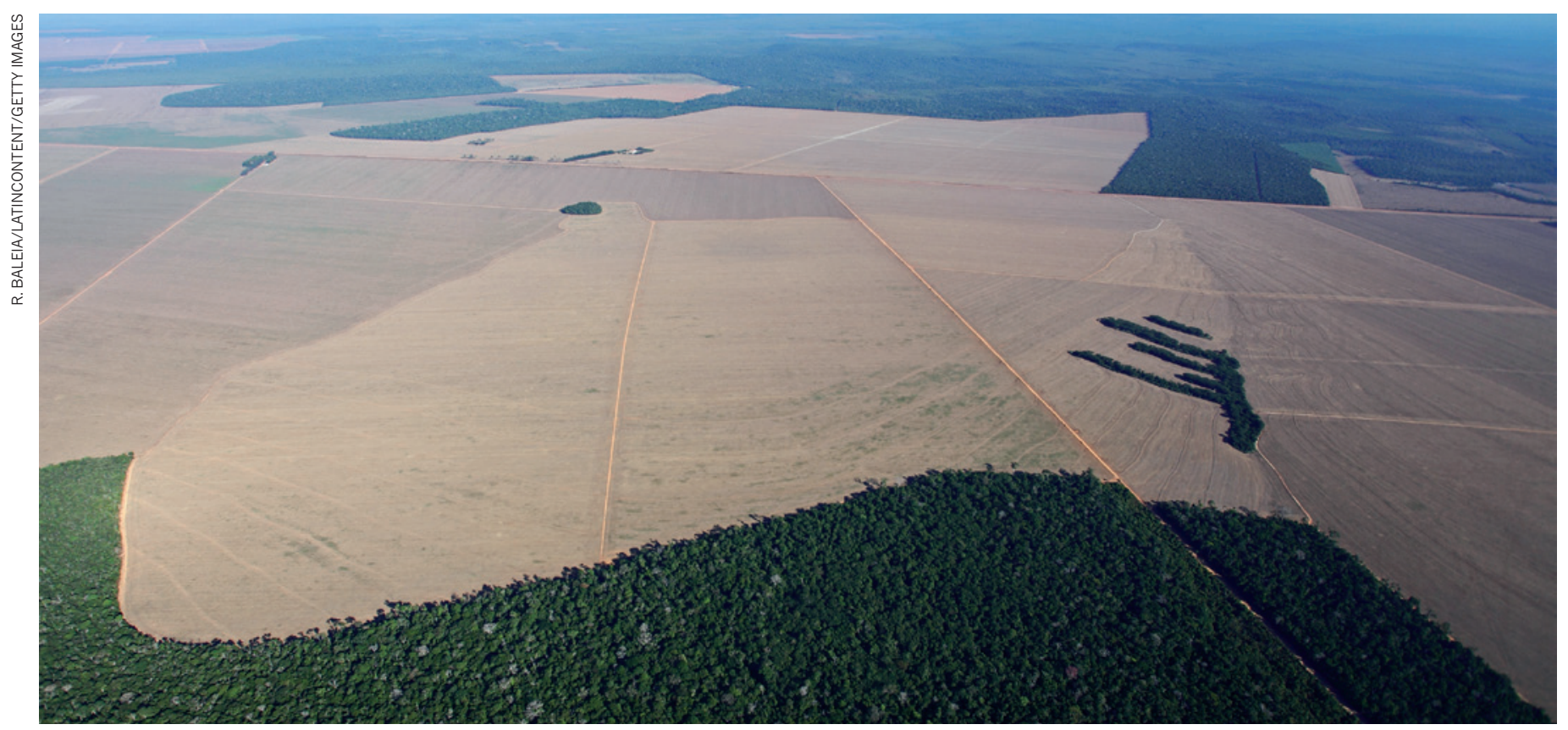

Soya bean farming in the Amazon is rising along with food prices, contributing to an increase in the rate of deforestation for the first time in years.

\title{
Brazil revisits forest code
}

\section{Changes to legislation could undermine authorities' power to halt deforestation.}

\section{BY JEFF TOLLEFSON}

$\mathrm{A}$ tough-minded law has boosted Brazil's environmental record in recent years by helping to drive the rate of destruction in the Amazon rainforest to historic lows. But a backlash in the hinterlands is threatening to weaken the country's forest code and push deforestation rates back up again.

Brazil's National Institute for Space Research (INPE) began reporting spikes in deforestation in March, two months before the nation's House of Representatives passed a bill to change the law that governs forests, which has been in force since 1965. The legislation includes clauses supported by agribusiness and small landowners that scale back federal authority and grant immunity from prosecution for all deforestation before 2008. The bill is now pending in the Senate - and is opposed by the administration of President Dilma Rousseff — but some observers

say that the debate alone has emboldened landowners to clear more land.

The tensions have been fuelled by high prices for commodities such as soya beans and beef, which have driven up demand for arable land while giving farmers and ranchers the cash they need to bring in chainsaws and bulldozers, says Dan Nepstad, a US ecologist who works with the Amazon Environmental Research Institute in Brasília. Meanwhile, he says, authorities are stuck trying to enforce a law that is strict, complex and difficult to comply with. "What Brazil has created is in many ways sort of the perfect recipe for a rural insurrection," Nepstad says.

But the Rousseff administration is not

\section{DNATURE.COM}

For more on agriculture in the Amazon, see: go.nature.com/dpkkvr backing down. Deforestation causes some $15 \%$ of global greenhousegas emissions and 75\% of Brazil's. Rousseff's predecessor, Luis Inácio
Lula da Silva, promised during the $2009 \mathrm{cli}-$ mate talks in Copenhagen that Brazil would cut deforestation by $80 \%$ by 2020 . Although Rousseff is not known as an environmentalist, she has maintained Lula's pledge and sent hundreds of law-enforcement officers into the Amazon as deforestation spiked.

The world will get its first glimpse of the results later this month, when the INPE releases its preliminary analysis of the annual deforestation season that ended in July. Some analyses already indicate that the steppedup enforcement has helped. According to an analysis of satellite data by the non-profit research institute Imazon in Belém, deforestation was actually $42 \%$ lower this June than last.

"Deforestation is going to increase in 2011, but it won't be a big jump," says Carlos Souza, a remote-sensing scientist who heads Imazon's satellite analysis. Imazon says that cumulative deforestation between August 2010 and 
- June 2011 rose by $15 \%$ compared with the same period the season before. If that number holds up in the final analysis using higher resolution satellite data, it would still be the second lowest loss on record (see 'Clearing the Amazon'). "We could say that the situation is still under control," says Souza.

Many scientists fear that the new law will cause further backsliding. For now, all landowners in the Amazon must maintain forest on $80 \%$ of their land, and those who had cleared illegally must reforest to that level. The House bill, however, would create exemptions for small landowners, and allow state governments to adjust the $80 \%$ rule.

All told, the changes could legalize the clearing of more than 220,000 square kilometres - an area nearly the size of the United Kingdom - according to an analysis by researchers at the University of São Paulo. Thomas Lovejoy, a tropical ecologist at the Heinz Center in Washington DC, says that the bill is a "recipe for Amazon dieback", a feedback loop that decreases rainfall and could convert vast swathes of rainforest into savannah.

But the bill could still be reformed in the Senate. Nepstad is pushing for an affordable way for older violators to comply, and for a credible punishment for new offenders. He says that the government needs to start investing in schemes to protect forest carbon and rewarding frustrated landowners who have obeyed the law while their neighbours cleared more land. If the law can't be enforced, he adds, the alluring profits of agriculture could lead to a "new wave" of deforestation.

Although rural interests have dominated the debate so far, most people share the concerns of the scientific community, says Luiz Martinelli, an ecologist at the University of São Paulo in Piracicaba who is analysing the legislation for senators. A national poll conducted in June by environmental groups found that $85 \%$ of Brazilians rate forest protection above agricultural production. "Brazilian society is kind of sick of this deforestation drama," Martinelli says..

\section{CLEARING THE AMAZON}

Law enforcement has helped reduce deforestation in the Brazilian Amazon, but early analyses suggest it will rise in 2011.

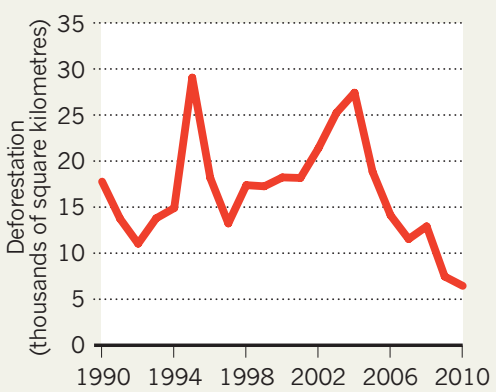

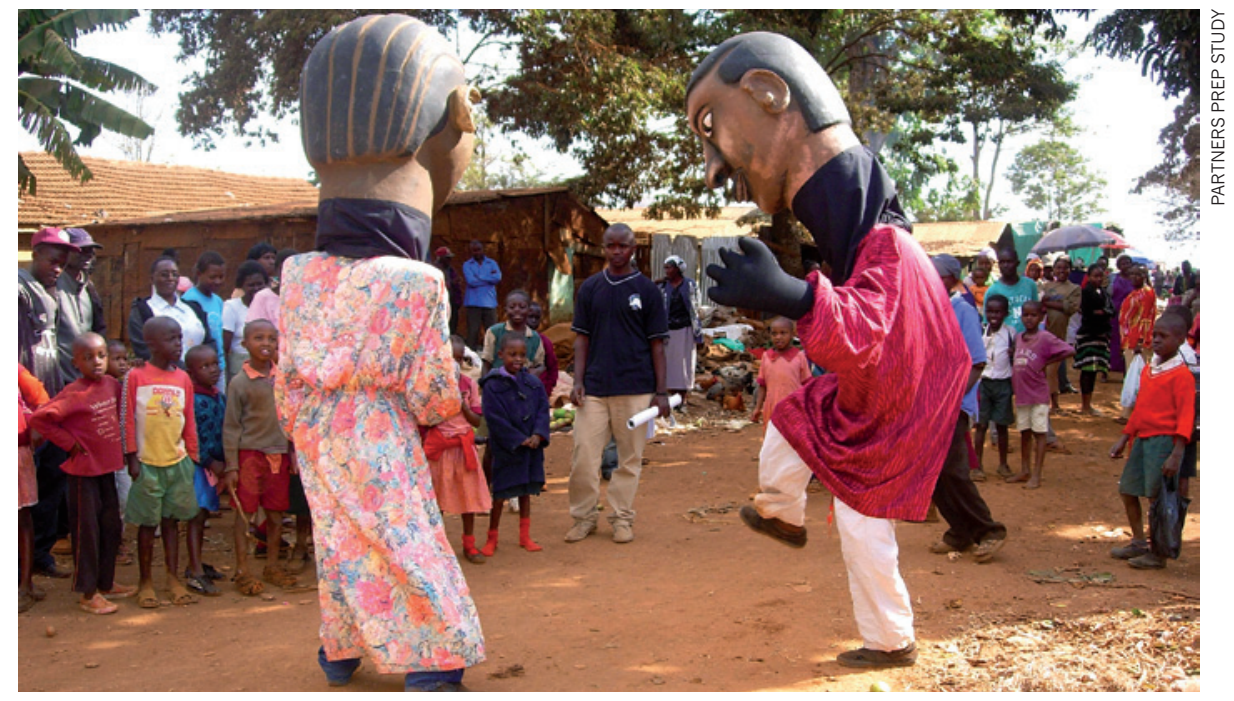

Public-health workers in Thika, Kenya, perform a skit to advertise a prophylactic HIV drug trial.

DRUG DEVELOPMENT

Human behaviour complicates prophylactic measures.

\section{BY ERIKA CHECK HAYDEN}

$\mathrm{W}$ hen the US Food and Drug Administration approved Viagra in 1998, officials never considered one possible side effect of the drug: higher rates of sexually transmitted diseases among men who, thanks to Viagra, would become more sexually active. A powerful tool in the fight against HIV is raising similar questions about the possibility of unintended public-health consequences if drugs are approved for use in healthy people and cause them to alter their behaviour.

Several studies in the past year have reported that the very drugs used to treat people with HIV can also stop healthy people from becoming infected (see table). But people taking the drugs may adopt riskier behaviours because they feel protected - a phenomenon known as 'risk disinhibition' - undermining the benefit of the drugs and potentially infecting others. Moreover, those who become infected while taking the preventive regimen might develop drug-resistant viruses that they could then transmit to others. "You have this wonderful scientific breakthrough," says Kevin Frost, chief executive of the Foundation for AIDS Research in New York City. "But what are the practical implications?"

Researchers will mull over these issues on 19 August at a meeting convened by the Forum for Collaborative HIV Research in Washington DC. The questions have become more

urgent since January, when the drug firm Gilead of Foster City, California, announced that it plans this year to ask the Food and Drug Administration (FDA) to approve its HIV drug Truvada for use in healthy people - in what is known as pre-exposure prophylaxis, or PrEP. Truvada, which contains the antiretroviral drugs tenofovir and emtricitabine, has been used in many of the PrEP trials. In the three clinical trials that have reported benefits for PrEP so far, once-a-day pills have cut a per-

"You have this wonderful scientific breakthrough. But what are the practical implications?" son's risk of acquiring HIV by between $44 \%$ and $73 \%$, a variation that is due primarily to differences in how strictly patients stuck to the daily regimen. Although the need for PrEP is greatest in poor countries, approval in the United States could greatly expand the market for Truvada, which generated US $\$ 2.65$ billion in sales last year.

But asking the FDA to evaluate questions about risk disinhibition and drug resistance might push the agency into uncharted territory. "When you're talking about a population issue, is that something that the FDA should be looking at at all?" asks Jur Strobos, deputy director of the Forum for Collaborative HIV Research.

The clinical trials don't offer clear guidance. Some of the successful trials found that people on PrEP actually used condoms more 